\title{
Office building retrofitting strategies: multicriteria approach of an architectural and technical issue
}

\author{
Emmanuel Rey \\ Bauart Architectes, Espace de l'Europe 3a, CH-2002 Neuchâtel, Switzerland
}

\begin{abstract}
In the context of an increasing number of retrofitting projects and greater consideration for the criteria of sustainability, architects and engineers are looking for a global optimization of existing buildings and therefore need to multiply comparisons between different possible variants. In order to structure the approach of this complex process, research carried out with the support of the Swiss Academy of Engineering Sciences (SATW) and the Swiss National Energy Research Foundation (NEFF) in the framework of the European Master in Architecture and Sustainability has made it possible to develop a multicriteria assessment methodology for office building retrofitting strategies applied to different case studies. The present article presents a synthesis of this research and an explanation of the method as a contribution to a global vision of the retrofitting process.
\end{abstract}

(C) 2004 Elsevier B.V. All rights reserved.

Keywords: Office building; Retrofitting strategies; Double-skin façade; Multicriteria assessment

\section{Introduction}

\subsection{Characteristics of the office building stock}

The demand for buildings specifically conceived for administrative work only arose in the 1950s. This sector is therefore characterized by a relatively late development, but also by major architectural, constructive and technical developments [1]. The observation of many Swiss office buildings, built during the last two centuries, has made it possible to globally identify six building categories from different periods which each present specific characteristics. The connection of these categories with quantitative data reveals that the major part of the office building stock-almost $65 \%$-is currently in the retrofitting phase, that is to say all office buildings built between 1947 and 1989 [2] (Fig. 1).

\subsection{The notion of retrofitting strategy}

As with every construction, office buildings are subject to physical and functional obsolescence. Regular maintenance can slow down this process, but after a certain time larger interventions become inevitable. The life duration of the constitutive elements of a building varies considerably. In

E-mail address: rey@bauart.ch (E. Rey). office buildings, it spans from some months for certain interior fittings to more than 30 years for façade elements. The necessity of an intervention on the façade is generally determining for the development of a retrofitting project. The duration of a retrofitting cycle can therefore be estimated at almost 25-30 years.

Operations made at that time may concern many different elements and aim at many different goals (for example, growth of building value, adaptation to new standards). In order to structure the approach to this complex process, it is necessary to use an inclusive notion, namely the idea of a retrofitting strategy. This can be defined as a set of interventions, dictated by a coherent architectural attitude and technically optimized, in particular through a full coordination of the interventions on the sheathing surfaces and the technical installations.

In a retrofitting project, the architectural attitude is above all characterized by the option taken with regard to the initial substance and by the degree of the induced modification. Observation of many projects has shown that in the case of office building renovations the intervention on the original façade is particularly significant, as it is linked to work on the technical installations. Three main types of strategy can be identified:

- the stabilization strategy (STA), which consists of a set of incremental interventions that do not fundamentally 


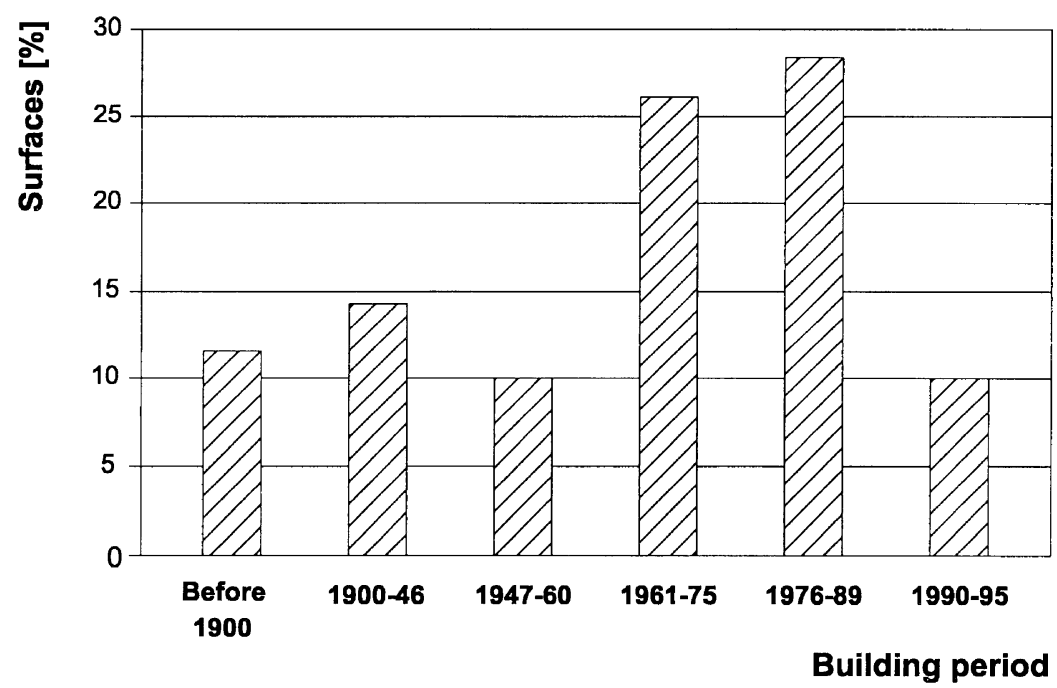

Fig. 1. Office building categories according to their construction period (source: WUEST and partners, Banque de données du parc immobilier suisse, Zürich, 1996).

modify either the substance or the appearance of the building;

- the substitution strategy (SUB), which consists of a complete change of certain elements and transforms simultaneously the substance and the appearance of the building;

- the double-skin façade strategy (DSF), which consists of partially stabilizing the existing façade and adding an new glass skin. This strategy involves a complete metamorphosis of the building's appearance, but maintains a large portion of the original substance. There are several types of double-skin façade. Given the usual typologies of existing office buildings and a high number of floors, only a device with mono-lateral ventilation, that works floor-by-floor and presents an acceptable risk of overheating in summer, has been considered here [3].

\section{Multicriteria assessment methodology}

\subsection{Selection of the criteria}

Concurrently with their architectural impact, the different strategies also present considerable variations in terms of performance. The objectives of the multicriteria assessment methodology developed in this research are to structure a comparison process that takes into consideration these multiple variations. The assessment is based on a selection of criteria, made among the numerous ones identified for the sustainable development of the built environment [4]. This choice has focused on a homogeneous integration of criteria belonging to the three main fields of sustainability: environmental, sociocultural and economic criteria have been considered simultaneously (cf. Table 1).

Table 1

Selected criteria and weight sets

\begin{tabular}{|c|c|c|c|c|}
\hline & Weigh & & & \\
\hline & $\mathrm{P} 1$ & $\mathrm{P} 2$ & P3 & $\mathrm{P} 4$ \\
\hline Environmental criteria & $1 / 3$ & $2 / 3$ & $1 / 6$ & $1 / 6$ \\
\hline Annual energy use for heating, $E_{\mathrm{h}}\left(\mathrm{MJ} / \mathrm{m}^{2}\right.$ per year $)$ & $1 / 9$ & $2 / 9$ & $1 / 18$ & $1 / 18$ \\
\hline Annual electricity use, $E_{\mathrm{el}}\left(\mathrm{MJ} / \mathrm{m}^{2}\right.$ per year $)$ & $1 / 9$ & $2 / 9$ & $1 / 18$ & $1 / 18$ \\
\hline Annual emissions, GWP $\left(\mathrm{kg}_{\mathrm{eq}} \mathrm{CO}_{2} / \mathrm{m}^{2}\right)$ & $1 / 18$ & $1 / 9$ & $1 / 36$ & $1 / 36$ \\
\hline Annual emissions, AP $\left(\mathrm{kg}_{\mathrm{eq}} \mathrm{SO}_{2} / \mathrm{m}^{2}\right)$ & $1 / 18$ & $1 / 9$ & $1 / 36$ & $1 / 36$ \\
\hline Sociocultural criteria & $1 / 3$ & $1 / 6$ & $2 / 3$ & $1 / 6$ \\
\hline Summer thermal comfort (daily overheating), $K_{\mathrm{h}}(\mathrm{K})$ & $1 / 9$ & $1 / 18$ & $2 / 9$ & $1 / 18$ \\
\hline Acoustic comfort (noise level at workplace), $L(\mathrm{~dB})$ & $1 / 9$ & $1 / 18$ & $2 / 9$ & $1 / 18$ \\
\hline Visual comfort-natural lighting, DLF (\%) & $1 / 18$ & $1 / 36$ & $1 / 9$ & $1 / 36$ \\
\hline Visual comfort-artificial lighting, $S<300 \mathrm{~lx}(\%)$ & $1 / 18$ & $1 / 36$ & $1 / 9$ & $1 / 36$ \\
\hline Economic criteria & $1 / 3$ & $1 / 6$ & $1 / 6$ & $2 / 3$ \\
\hline Renovation costs (investment), $I\left(\mathrm{Frs} / \mathrm{m}^{2}\right)$ & $1 / 6$ & $1 / 12$ & $1 / 12$ & $1 / 3$ \\
\hline Annual on-going charges, $C\left(\mathrm{Frs} / \mathrm{m}^{2}\right.$ per year) & $1 / 6$ & $1 / 12$ & $1 / 12$ & $1 / 3$ \\
\hline
\end{tabular}




\subsection{Multicriteria assessment}

Moreover, to determine which retrofitting strategy is globally the most efficient, it is necessary to carry out an aggregation of the results obtained for each criterion. The originality here is the use of the mathematical algorithm of the ELECTRE family methods, based on a partial aggregation instead of a classical utility function. This method does not give a global mark to the compared variants, but establishes a ranking list by comparing them two-by-two and criterion-by-criterion. This approach notably presents the advantage that it offers a subtler ranking process, nearer to the implicit modeling of every decision-maker [5].

The method involves the definition of three threshold values (reference to fuzzy logic), which permit the user to take into consideration the intensity of the performance difference for each criterion [6]. Between the evaluation of each strategy for each criterion and the final multicriteria ranking list of the different strategies compared, several calculation stages are necessary. As the full explanation of this mathematical algorithm is outside the scope of the present paper, only the basic principles are summarized here:

\section{- Definition of the weights and thresholds}

For each criterion $\left(g_{i}\right)$, it is necessary to define a weight $\left(w_{i}\right)$, in other words to give a coefficient of importance and three threshold values: preference $\left(p_{i}\right)$, indifference $\left(q_{i}\right)$, and veto $\left(v_{i}\right)$. In this case, four different weight sets (P1-P4) have been applied to show the influence of the attributed importance to the different groups of criteria.

\section{- Criterion-by-criterion comparison}

The strategies (STA, SUB, DSF) are then compared two-by-two and criterion-by-criterion. For each criterion, the difference observed between two performance values is compared with the three predefined thresholds. This comparison gives a value $\left(c_{i}\right)$, respectively $\left(d_{i}\right)$, between 0 and 1 , which defines either a concordance or discordance index (cf. Fig. 2).

\section{- Global outranking relation}

A strategy "a" outranks another strategy "b" when it is as good as "b" for a majority of criteria (concordance condition), without being too bad in relation to the other criteria (undiscordance condition). These conditions are verified through the calculation of a global concordance index (based on the obtained $c_{i}$ values and the considered weight set) and a credibility index (which qualifies the intensity of the outranking relation and fixes the incomparability tolerance). These two indexes give for each compared strategy pair $(a, b)$ one of the following relations: a $\mathrm{R}$ b (incomparability), $\mathrm{P} \mathrm{P}$ or $\mathrm{b} \mathrm{P}$ a (preference), $\mathrm{a} \mathrm{I} \mathrm{b}$ (indifference).

- Ascending and descending distillation

To establish the global ranking list, it is necessary to consider then all outranking relations between strategies (compared two-by-two), taking into account the respective credibility index. This procedure, named distillation, counts for each strategy the number of other strategies that it outranks (ascending distillation) and the number of other strategies that outrank it (descending distillation). This operation involves a relatively complex algorithm, whose application is possible thanks to the use of the ELECTRE III software.

- Ascending and descending ranking lists

These distillations lead to two ranking lists (ascending and descending), that do not necessarily give the same preference order. Certain strategies can clearly be compared to others and have the same position in both outranking lists, but others could be more difficult to compare and occupy different positions in each ranking list.

\section{- Final ranking list}

In order to establish the final ranking list, the software provides an intersection of the two ascending and descending ranking lists (reference to whole theory). The outcome is:

○ Strategy "a" can be before strategy "b" in the final ranking list only if it is before "b" in one ranking list and before or equal with "b" in the other one.

- Two strategies can be equally placed in the final ranking list only if they belong to the same class in both ascending and descending ranking lists.

- Two strategies "a" and "b" are incomparable if "a" is before " $\mathrm{b}$ " in one ranking list and " $\mathrm{b}$ " is before " $\mathrm{a}$ " in the other one.

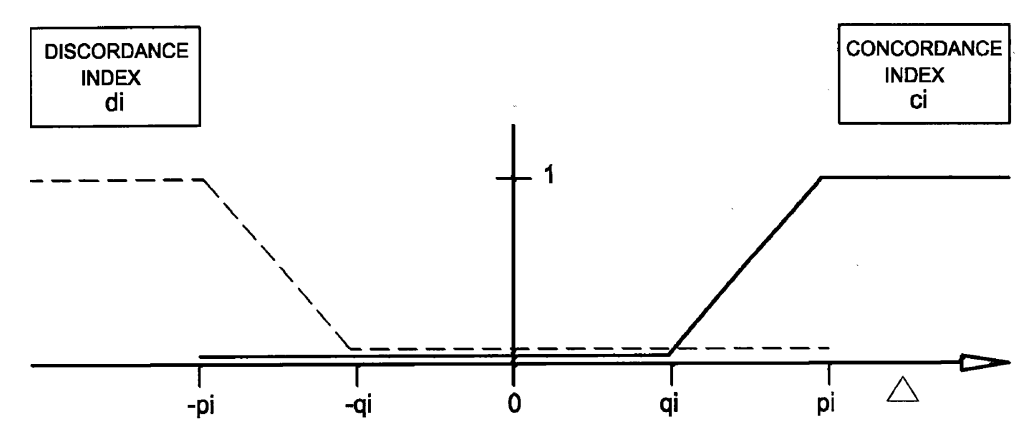

$\triangle=$ Performance difference between compared buildings according to criterion i

Fig. 2. Definition of concordance and discordance indexes [6, p. 230]. 
The main advantages of this approach is the transparency of the method, the fact that it takes into account several qualitative degrees (preference, indifference and veto thresholds), the impossibility to compensate an unacceptable performance (notion of veto value), the absence of attributed grades (conservation of the usual units) and the possible coming to light of incomparability.

\section{Case studies}

The applicability of this approach has been verified in the framework of three case studies, which investigated three office buildings that are typical for different architectural periods (cf. Figs. 3-5).

Simulations of the different strategies were carried out for each building to obtain first an evaluation by criterion. This was based on existing data, numerical simulations with different specific computer programs (for example, Lesosai, Lesocool, Lesodial, Relux, Acousalle) and cost estimations from specialized firms. Three examples of these estimations by criterion are given in Figs. 5-8. The different results, in-

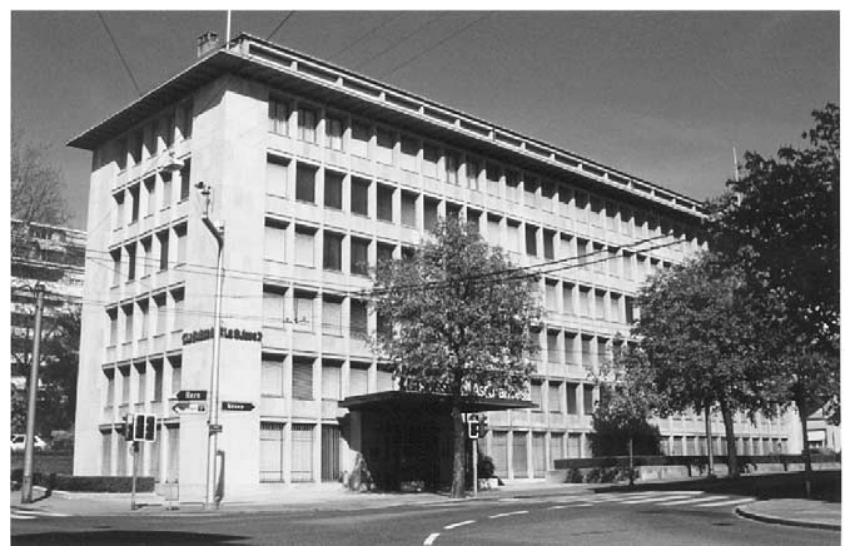

Fig. 3. Case study 1: La Suisse office building in Lausanne, built in 1952-1954 (Arch. Thévenaz and Bonnard).

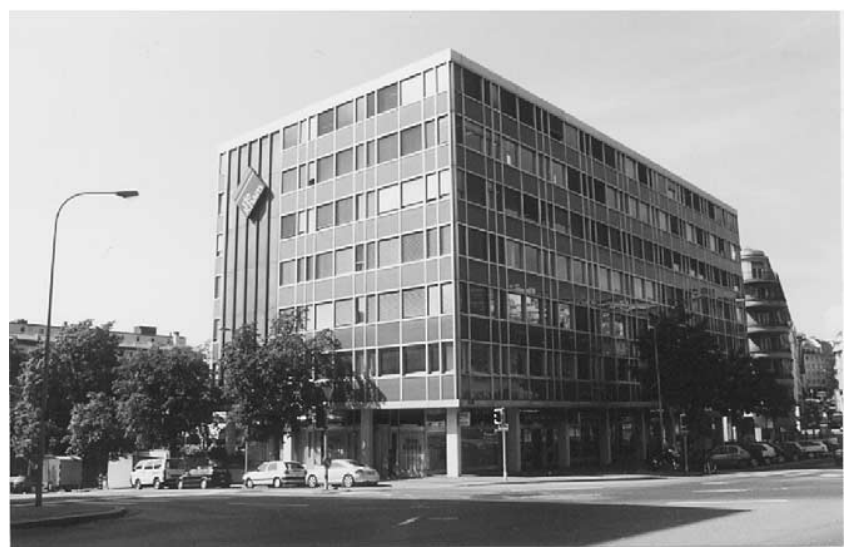

Fig. 4. Case study 2: De Rahm office building in Lausanne, built in 1964-1965 (Arch. Bonnard and De Rahm).

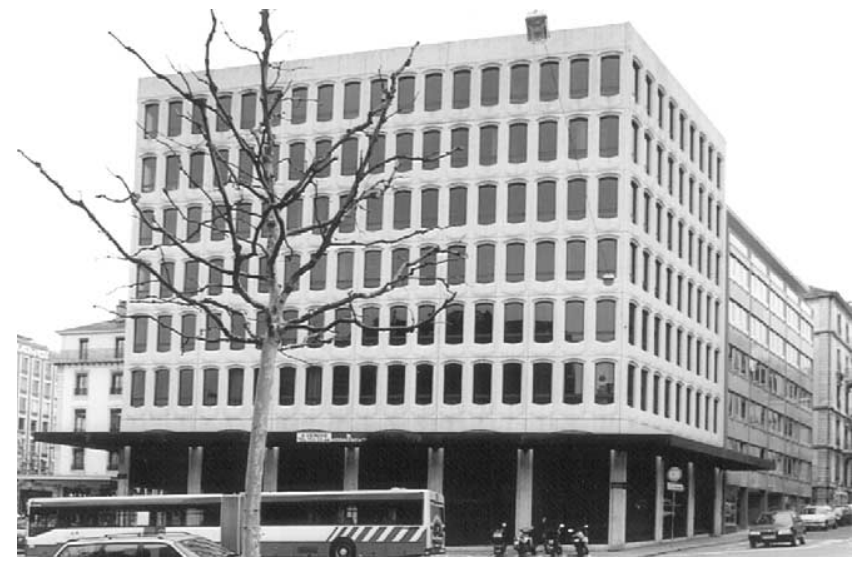

Fig. 5. Case study 3: Cours de Rive office building in Geneva, built in 1976-1978 (Arch. J.-L. Ardin).

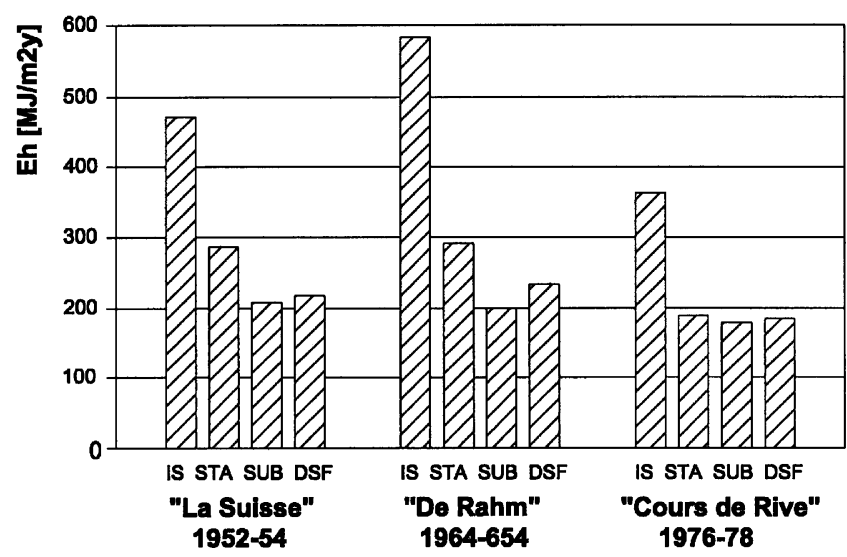

Fig. 6. Evaluation by criterion (IS: initial situation): example of environmental criterion annual energy use for heating (Lesosai simulations).

tegrated then into the multicriteria assessment method, made it possible to obtain, for each case study, the strategy ranking list for the four sets of weights (Fig. 8).

The first case study looked at the La Suisse office building in Lausanne (1952-1954), which is characterized by

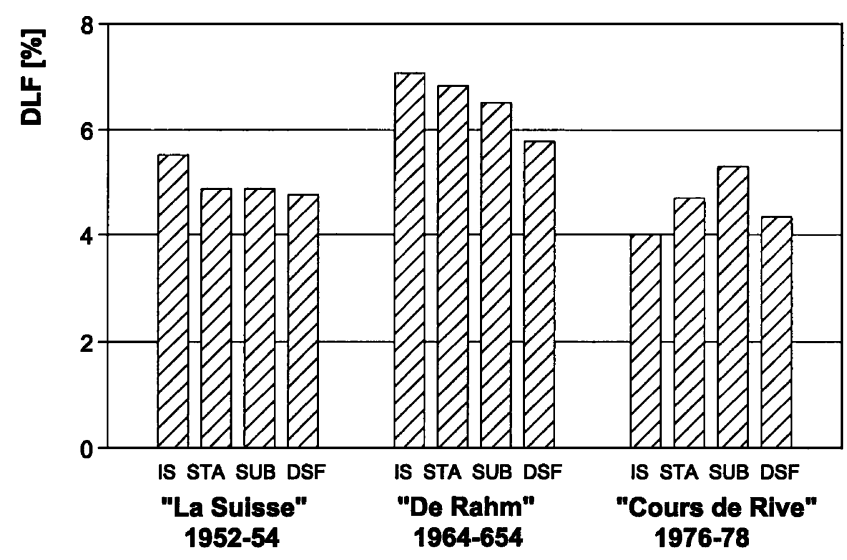

Fig. 7. Evaluation by criterion: example of sociocultural criterion: visual comfort (Lesodial simulations of daylighting). 


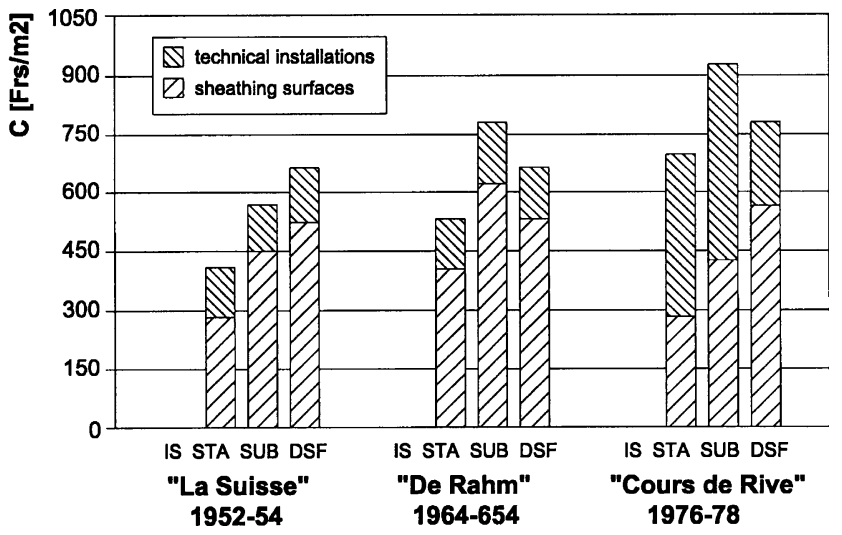

Fig. 8. Evaluation by criterion: example of economic criterion: retrofitting costs (estimations carried out in collaboration with specialized firms).

structural façades, a framed concrete structure and naturally ventilated offices, typical of constructions in the 1950s [7]. The rank lists of the different strategies tends to show that the stabilization strategy offers the highest performance overall for this building. Indeed, this strategy obtains the first rank for the four weight sets, except when the environmental criteria are considered as predominant (P2). In this case, the most appropriate one is the substitution strategy with a higher thermal quality of the façades. By contrast, the double-skin façade strategy ranks last for each weight set (cf. Fig. 9).

The second case study considered the De Rahm office building in Lausanne (1964-1965), which is representative of the buildings built during the period 1960-1975 and strongly influenced by the principles of international style (independent structure and suspended glass façades). The simulations show in this case more variations between the different rank lists. The retrofitting strategies that imply a large degree of transformation, namely the substitution and the double-skin façade strategy, seem to be more appropriate, except when the economic criteria are considered as preponderant. In this case, the stabilization strategy distinguishes itself by a favorable ratio between its low costs and its performance with regard to comfort and energy consumption (cf. Fig. 10).

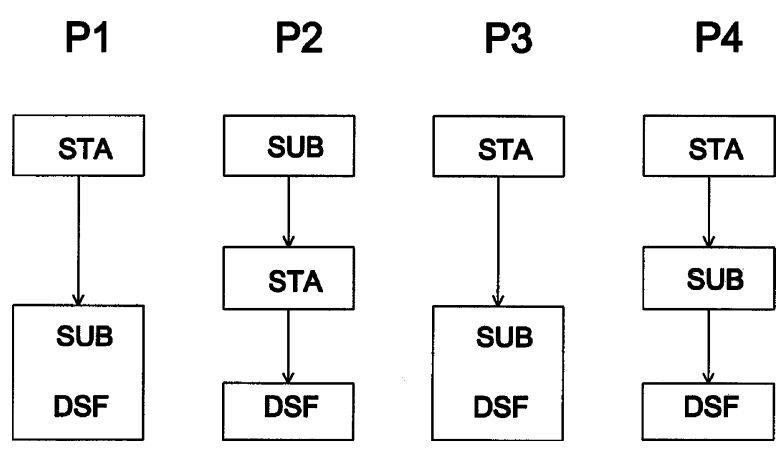

Fig. 9. Multicriteria evaluation: rank lists obtained by the different retrofitting strategies for the La Suisse office building (1952-1954).

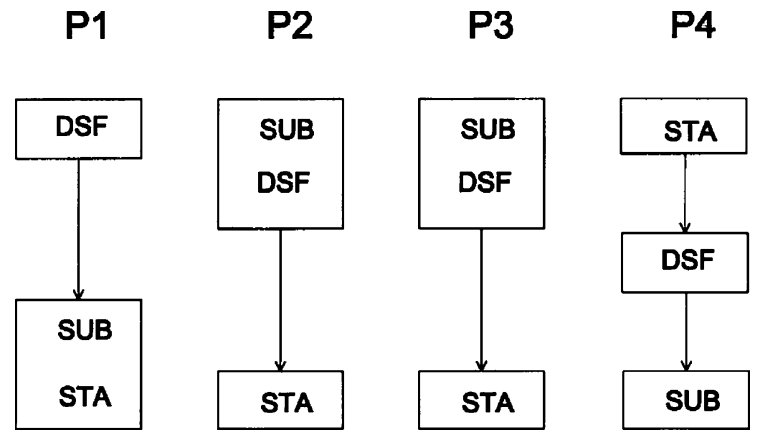

Fig. 10. Multicriteria evaluation: rank lists obtained by the different retrofitting strategies for the De Rahm office building (1964-1965).
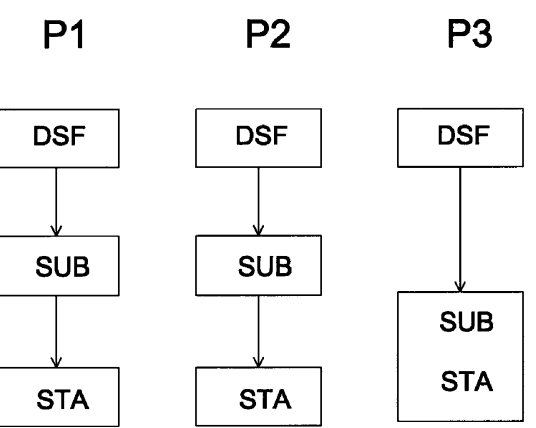

\section{P4}

Fig. 11. Multicriteria evaluation: rank lists obtained by the different retrofitting strategies for the Cours de Rive office building (1976-1978).

The third case study was of the Cours de Rive office building in Geneva (1976-1978), which is representative of the period which lasts from the petroleum crisis to the end of the 1980s. It is characterized by a massive constructive system (prefabricated concrete panels) and large technical installations (mechanical ventilation and air conditioning). For this building, the double-skin façade strategy presents the highest level of performances for each weight set, followed by substitution and stabilization. The good position of the double-skin façade strategy must be linked directly with the hypothesis of the possibility of giving up the air conditioning and resorting to a simpler solution based on the natural ventilation and night cooling effect (cf. Fig. 11).

\section{Conclusion}

Office building retrofitting strategies are influenced by numerous parameters. The research presented in this paper has made it possible to scrutinize the issues specific to this complex process and to develop a structured multicriteria assessment methodology, which simultaneously takes into account environmental, sociocultural and economic criteria. The application of this method to concrete case studies has made it possible to demonstrate the interest of the proposed approach, and also to confirm the hypothesis that the classification of the retrofitting strategies varies according to identified factors (time of building, criteria weights). 
Beyond the tendency shown in the ranking lists, it is necessary to note that other important factors could also have an influence on the definitive choice. These parameters, that can modify the preference given by the performance evaluation, refer essentially to user requirements and architectural considerations.

Unlike for new constructions, the question of user requirements also plays a role during the site phase in a retrofitting project. The possibility of maintaining activities during the operation can be decisive in the final choice of a strategy. For some types of buildings, the substitution strategy can present a marked disadvantage, especially for buildings with suspended glass façades (1961-1975 period). These aspects can be attenuated if the project progresses in clear successive steps.

Other elements related to the building's use can have great importance in the choice of the most suitable strategy. Systems based on natural ventilation and passive cooling principles often require greater collaboration from users and can be unacceptable in certain situations. The choice of passive systems is sometimes difficult to make, especially in buildings that are already designed with air-conditioning devices and in buildings that are occupied by many different companies. Passive strategies are adapted for office buildings with a relatively simple technical degree and with moderate internal heat gains. Conference rooms, computer rooms and calculation centers should generally have an auxiliary mechanical device. The design principle should try to concentrate this type of room in one part of the building and to use technologies with reduced energy consumption (recuperation of extracted air in winter, free cooling in summer, etc.).

A retrofitting project always generates a principle of modification, which should be chosen not only with regard to the performance of the envisaged strategy, but also in relation to the degree of degradation, the architectural quality and the historical value of the original substance. Taking into account these parameters can sometimes balance the strict application of the results obtained from the ranking lists. In that sense, the stabilization and the substitution strategy lead the planners towards a more radical decision, either for conservation or for replacement. In accordance with its degree of performance (energy, comfort, costs, etc.), notably in the case of a building with suspended glass façades, the double-skin strategy can offer an interesting alternative, which subtly allies the conservation of the original substance and the metamorphosis of the building image.

The research has also brought to the fore the strong interaction between the multiple possible interventions and the considered performance criteria. Looking for a global optimization of the buildings, architects and engineers should therefore favor interdisciplinary and integrated approaches. In that sense, the different case studies have demonstrated that it is possible to improve different aspects of the building in one go. In particular, it is not contradictory to aim simultaneously at a coherent esthetical approach, a reduction in energy consumption and an improvement in comfort [8].

As the results of the different case studies have shown, the method developed can become a real tool to support the decision making process. Moreover, it offers an efficient possibility to compare the performance degrees of the different retrofitting strategies which can be envisaged. Multiple factors play a role in this choice, so the retrofitting project can be seen as what we can call a knowledge project. This global vision can give the deciders all the necessary elements for a possible subsequent justification of the options taken. Through the development of assessment methods, the performance of each retrofitting strategy can find its right place in the framework of this knowledge project. This evaluative approach is part of a larger evolution in the field of built environment practices, which tends to integrate sustainability criteria directly into the design process. The objectives of this holistic approach are to find solutions that are technically appropriate, environmentally sound, financially viable and socioculturally valuable [9].

\section{References}

[1] A. De Herde, et al., Evolution de la typologie de bureau. Project SOLINFO, UCL/Architecture et climat, Louvain-la-Neuve 1994.

[2] WUEST and partners, Banque de données du parc immobilier suisse. Zürich, 1996.

[3] A. Faist, et al., La façade double-peau, EPFL/LESO-PB, Lausanne, 1998.

[4] Societe des ingenieurs et architectes (SIA), Constructions: critères d'un développement durable, Documentation D 0164, SIA, Zürich, 2000.

[5] A. Schaerlig, Pratiquer Electre et Prométhée. Un complément à décider sur plusieurs critères, PPUR, Lausanne, 1996.

[6] C.-A. Roulet, et al., ORME: a multicriteria ranking methodology for buildings, in: Proceedings of the CISBAT'99, Lausanne, October 1999, pp. 227-232.

[7] E. Rey, Le bâtiment administratif de "La Suisse Assurances" à Lausanne. Evaluation de différentes stratégies de rénovation. Matières 4 (2000) 106-111.

[8] E. Rey, Evaluation multicritères des stratégies de rénovation de bâtiments administratifs. Ingénieurs et architectes suisses 29/30 (2000) 304-308.

[9] E. Rey, Architecture et développement durable: de la théorie à la pratique, in: Architecture et écologie, l'art de créer, Centre cantonal Info-Energie, Neuchâtel, June 2001. 